\title{
EXPLORING THE INTEGRATION OF LAST PLANNER® SYSTEM, BIM, AND CONSTRUCTION SIMULATION
}

\author{
Amila N. Wickramasekara', Vicente A. Gonzalez², Michael O'Sullivan ${ }^{3}$, \\ Cameron G. Walker ${ }^{4}$, Mani Poshdar ${ }^{5}$, and Fei Ying ${ }^{6}$
}

\begin{abstract}
Much attention has been paid to Computer Simulation and Modelling (CSM) in the research circles of construction over the last sixty years. However, it has not been widely adopted within the construction industry. In this paper, we explore theoretically the potential of the integration between CSM, the Last Planner System (LPS) and Building Information Modelling (BIM) to accelerate the uptake of CSM in the construction industry. To do so, a review of the literature to identify the synergies between CSM, LPS and BIM was undertaken, where it was found that little research has been done associated with their integration and linkages as a whole. We found that an explicit integration of these three domains has the potential to enhance and accelerate the adoption of CSM in construction as it provides the opportunity to engage construction project stakeholders towards CSM, focusing on domain-specific characteristics and recent advancements of construction management. Based on our review, we propose five research questions to guide the development of a domain-specific construction simulation framework to be considered in future research.
\end{abstract}

\section{KEYWORDS}

Last Planner ${ }^{\circledR}$ System, integration, collaborations, computer simulation

\section{INTRODUCTION}

Computer Simulation and Modeling (CSM), understood as the "experimentation with a simplified imitation (on a computer) of an operations system as it progresses through time, for better understanding and/or improving that system" (Robinson 2014), has been investigated by construction researchers since 1960 (AbouRizk et al. 2011). In general,

$1 \quad \mathrm{PhD}$ student, Department of Civil and Environmental Engineering, The University of Auckland, Auckland, New Zealand, awic135@aucklanduni.ac.nz, orcid.org/0000-0002-4964-3539

2 Senior Lecturer, Department of Civil and Environmental Engineering, Founder and Research Lead Smart Digital Lab., The University of Auckland, 20 Symonds Street, Auckland, New Zealand, v.gonzalez@auckland.ac.nz, orcid.org/0000-0003-3408-3863

3 Senior Lecturer, Department of Engineering Sciences, The University of Auckland, Auckland, New Zealand, michael.osullivan@auckland.ac.nz, orcid.org/0000-0002-5621-4206

4 Associate Professor, Department of Engineering Sciences, The University of Auckland, Auckland, New Zealand, cameron.walker@auckland.ac.nz, orcid.org/0000-0003-3176-9341

5 Lecturer, Department of Built Environment Engineering, Auckland University of Technology, Auckland, New Zealand, mani.poshdar@aut.ac.nz, orcid.org/0000-0001-9132-2985

6 Senior Lecturer, School of Engineering, Computer and Mathematical Sciences, Auckland University of Technology, Auckland, New Zealand, fei.ying@aut.ac.nz, orcid.org/0000-0002-6355-5156 
CSM enables a better understanding of the system under study and supports its improvement (Robinson 2014). CSM also helps to recognize problem areas and provides feasible solutions at low-cost and low-pressure (AbouRizk et al. 2011). CSM as a decision-support tool has been widely applied in different domains, such as healthcare (Salleh et al. 2017), the military (Jnitova et al. 2017) and manufacturing (Jeon and Kim 2016). However, the extent to which CSM has been used within the construction domain has been limited compared to other domains (Abdelmegid et al. 2020).

Despite all the attention that CSM has gained in construction academic circles in the last sixty years, the uptake of CSM in practice is still very limited. In that regard, Abdelmegid et al. (2020) has identified a number of barriers to adopting CSM within the construction industry, including lack of simulation knowledge among construction practitioners, nature and amount of data required for CSM, dynamic and risky nature of construction operations, and the temporary and unique nature of construction projects. These authors determined that these barriers fall into four main categories: (1) nature of construction projects; (2) simulation technology; (3) industry practitioners; (4) simulation research within the construction domain. Recent research about the integration of CSM and Building Information Modeling (BIM) (Lu and Olofsson, 2014; Jeong et al. 2016), and CSM and the Last Planner System (LPS) (Hamzeh et al. 2016; Abdelmegid et al. 2019) provides evidence for opening up new research avenues to explore the potential of the integration CSM-BIM-LPS with the aim of easing the acceptance of CSM by using well-known IT and lean-driven tools and methods in construction. BIM creates a digital and data platform for increased collaboration between project participants that facilitates the exchange and reuse of project information (Sacks et al. 2018). LPS is a lean-based production planning and control system for construction projects. Its implementation helps to improve the reliability of planning as well as decreasing the variability of the workflow (Ballard 2000; Gonzalez et al. 2008; Toledo et al. 2016). Therefore, it can be argued that if the implementation of CSM is linked with BIM and LPS, some of the barriers to CSM adoption in construction could be further alleviated. Also, developing a domain-specific CSM framework that integrates BIM and LPS facilitates the use of CSM in construction and enables more effective project production decision-making. As a result, the full potential of CSM can be brought to the construction industry, as has been done in other domains.

Accordingly, this paper's aim is to explore the possibility of developing a domainspecific CSM framework that integrates BIM, LPS with computer simulation. To reveal the existing links between them, a review of the literature was conducted within the Scopus database using combinations of the following keywords: "last planner system", "building information model", "computer simulation" within the Titles, Abstracts, and keywords. Forward and backward snowballing sampling was also used to ensure the inclusivity of the results. Moreover, research profiles of key authors in the construction field was considered for selecting relevant sources. A preliminary CSM framework was developed based on the review results.

\section{BACKGROUND}

In this section, we briefly introduce BIM, LPS and CSM.

\section{BIM}

BIM is a technology that consists of techniques and processes based on the utilization or sharing of digital information among stakeholders in a construction project (Hochscheid 
and Halin 2019). It enhances the communication between all stakeholders in a construction project through a centralized model (Gerges et al. 2019). Eynon (2016) reports that this digital information is consistent, classified and coherent, and this alone reduces waste in a team's efforts, as information is coming from a verified source and is being used consistently. Also, Sun et al. (2017) state that BIM can be used in several stages in the construction project life-cycle creating significant benefits for stakeholders and society. Many BIM functions that can be used in all stages in a construction project have been discussed in recent literature (Eastman et al. 2011; Sacks et al. 2010; Oskouie et al. 2012; Sacks et al. 2018). However, according to a survey conducted by Gholizadeh et al. (2018), 3D visualization, clash detection and constructability analysis are the most widely adopted BIM functions. 4D scheduling and 5D cost estimation are also being increasingly adopted by construction practitioners. Therefore, we consider these BIM functions as the point of departure to propose our conceptual methodology.

\section{LPS}

LPS is a production planning and control system based on lean principles that helps practitioners to manage uncertainties (Hamzeh et al. 2019). LPS mainly consists of five stages: Master Production Schedule (MPS), Phase Schedule, Lookahead Plan, Weekly Work Plan and Learning (Ballard 2000). Nikhil et al. (2017) state that LPS is based on a bottom-up approach, whereas traditional project management uses the top-down approach. To optimize the planning and execution of the construction operations, LPS supports with the "pull" system (Heigermoser et al. 2019). Gonzalez et al. (2008) found that improving the reliability of planning using LPS enhances project performance.

\section{CSM}

Al-Kaissy et al. (2019) reviewed CSM methods used in construction research and found that three simulation paradigms have been used: Discrete Event Simulation (DES), Agent-Based Modeling (ABM) and System Dynamics (SD). The use of hybrid simulation paradigms has also been discussed in construction literature (Naraghi et al. 2017; Bokor et al. 2019). Moreover, simulation-based optimization is becoming a popular topic among construction researchers nowadays (González et al. 2009; Zaki et al. 2019). A simulation study typically involves four phases: (1) conceptual modeling; (2) model development; (3) experimentation; and (4) implementation (Robinson 2014).

\section{Conceptual Modelling}

Robinson (2008) defines conceptual modeling for CSM as "a non-software specific description of the computer simulation model (that will be, is or has been developed), describing the objectives, inputs, outputs, content, assumptions and simplifications of the model". Also, this is the initial and most important step of a simulation study, where a model is abstracted from a proposed or real system. Within this phase, modelers recognize what has to be modeled and how the modeling is accomplished.

\section{Model Development}

This is the process of converting the conceptual modeling into the computer model (Robinson 2014). It can be done using appropriate simulation software or language.

\section{Experimentation}

During this phase, model inputs are changed to find the best alternative, and further analyses of simulation output can be done according to requirements. 


\section{Implementation}

This is the final step of a simulation study during which recommendations are made based on the best alternatives selected from the experimentation stage. Next, those recommendations are implemented, and the results of the implementations monitored for further improvements of the simulation-based decision-making process.

\section{INTERACTIONS BETWEEN BIM, LPS AND CSM}

The following sections discuss the studies that have been conducted during the past two decades on the integration of BIM, LPS and CSM within the construction domain.

\section{LPS WITH BIM}

Several studies on the use of BIM for improving the performance of LPS can be found in the recent construction literature. For example, Bhatla and Leite (2004) conducted a study to highlight waste reduction in lean construction and to increase collaboration with the project stakeholders. They presented a framework that integrated BIM with LPS at Master Schedule Level, Lookahead Planning and Weekly Work Planning. The importance of using 4D scheduling, BIM coordination meetings, clash detection of BIM functions have been highlighted within their framework. Garrido et al. (2015) demonstrated the applicability of a framework in two residential projects that integrates BIM and LPS. In this framework, they highlighted several interactions between BIM and LPS functions, namely: 4D model with the Master Plan; Request for Information (RFI) and clash detection with Lookahead Planning; systematic registration of demands for information with the Weekly Work Plan. The usefulness of a BIM information repository is clearly highlighted here. Tillmann and Sargent (2016) presented the advantages of integrating LPS with BIM for mechanical, electrical, plumbing and fire protection functions. Toledo et al (2016) also presented a Lean-BIM planning framework linking LPS with BIM for enhancing the performance of construction project management. They emphasized the importance of 4D model and RFI for the Lookahead Planning and Weekly Work Plan within the LPS. The framework was validated through a comparison of two case studies: one with only LPS, and one with both BIM and LPS. By integrating LPS with 3D visualization capabilities in BIM technology, Heigermoser et al. (2019) proposed a tool for managing construction operations, with their aim being to enhance productivity and diminish construction waste. Accordingly, the literature shows that that there are significant impacts of synergy between LPS and BIM in construction management. Also, it could be concluded that $3 \mathrm{D}$ visualization, 4D scheduling and clash detection were the most used BIM functions contributing to improving the performance of LPS.

\section{LPS WITH CSM}

During the past decade, several studies have been conducted using CSM to highlight the importance of the Lookahead Planning of LPS (Hamzeh et al. 2015; Hamzeh et al. 2016). They assessed the relationship between Task Made Ready (TMR), Percentage Plan Completed (PPC) and duration of a project. They discovered that the overall duration of a project can be reduced while at the same time improving PPC and enhancing the performance of Lookahead Planning. Abou-Ibrahim et al. (2019) investigated the impact of capacity planning on the duration and cost of a construction project using CSM. Capacity planning is an extremely important task in the Lookahead Planning when matching tasks workload (e.g. scheduled work) with the available resources (e.g. labor capacity). They discovered that both the selection of the method of capacity planning and 
the nature of the project significantly affect the cost and duration of the project. Furthermore, they reported that awareness of the characteristics of a project enhances the balance between the work quantity and the capacity. Abdelmegid et al. (2019) introduced a framework linking different stages of LPS and the conceptual modeling phase of the CSM process that can be used as a support tool for the effective implementation of LPS. Accordingly, the above-mentioned studies highlight the importance of the use of CSM for optimum decision making within the LPS.

\section{BIM WITH CSM}

During the last decade, several attempts have been made by construction academia to combine BIM with CSM to enhance the performance of the construction operations (Konig et al. 2012; Lu and Olofsson, 2014; Liu et al. 2015; Jeong et al. 2016). König et al. (2012) presented an intelligent approach to providing inputs for a simulation model by linking it to BIM, which handles modifications and various alternatives. In this approach, the accuracy of the interdependencies between activities can be checked and visually highlighted. Lu and Olofsson (2014) introduced an integrated BIM and DES framework including a dynamic database from which the DES model intelligently reads data. This framework significantly reduces the manual work related to the development and maintenance of the DES model. Also, it provides the opportunity to assess the performance of construction related to different designs, resource allocations and alternative use of construction methods without adjusting the simulation model. Liu et al. (2015) developed an automated construction planning approach focusing on off-site construction. A purpose-built simulation template providing a BIM-based interface was developed for efficient information exchange between the BIM model and the DES model for production lines. Jeong et al. (2016) presented a framework, aimed at improving the planning reliability, integrating BIM and CSM to predict productivity dynamics during the construction planning stage. This allows for adjusting construction plans with the updates of the BIM model. Also, this framework is applicable whenever delays occur and resources are changed, as activities are expressed in more detail. Osorio et al. (2018) also developed a simulator prototype integrating BIM and DES within a commercial game engine, thus enabling visualization capabilities that allow the user to interact in the 3D environment and gain a better understanding of the project. This tool uses DES to model the construction process and BIM to represent the physical characteristics of the project. However, this approach is limited to only a single construction activity and a limited number of experimental factors. These studies have shown the possibility of combining CSM with BIM by analysing specific areas of synergy. Accordingly, the use of BIM as an information repository for simulating a construction process has been highlighted. The literature also indicates the importance of using 3D visualization for a better understanding of the simulation results.

\section{LINKING BIM, LPS WITH CSM}

It is evident that there are explicit synergies between BIM, LPS, and CSM with the potential for enhancing the overall productivity of construction operations. We argue that a construction simulation framework that integrates BIM and LPS is useful to properly establishing those synergies. This to a great extent results in eliminating barriers to the adoption of CSM within the construction domain and improving the effectiveness of production decision-making in construction projects. 
Figure 1 shows the preliminary CSM framework that integrates BIM and LPS in different phases of a construction project. For the development of this framework, we consider the following stages in a construction project: conceptualization, initial design, detail design and construction. We argue that the important BIM functions and the components of LPS implemented within these stages can be usefully linked to CSM. Furthermore, although there are a large number of BIM functions associated with a construction project (Sacks et al. 2018), we use 3D visualization, 4D scheduling, 5D cost estimation, clash detection and maintaining a single information source for this framework. As mentioned earlier, the importance of 3D visualization, 4D scheduling and clash detection are discussed in the literature related to linking BIM, LPS and CSM within the construction domain. Also, we argue that because BIM functions have been rapidly adopted by construction practitioners (Gholizadeh et al. 2018), the use of these functions for the development of a CSM framework will be beneficial for increasing the uptake of $\mathrm{CSM}$ within the construction domain.

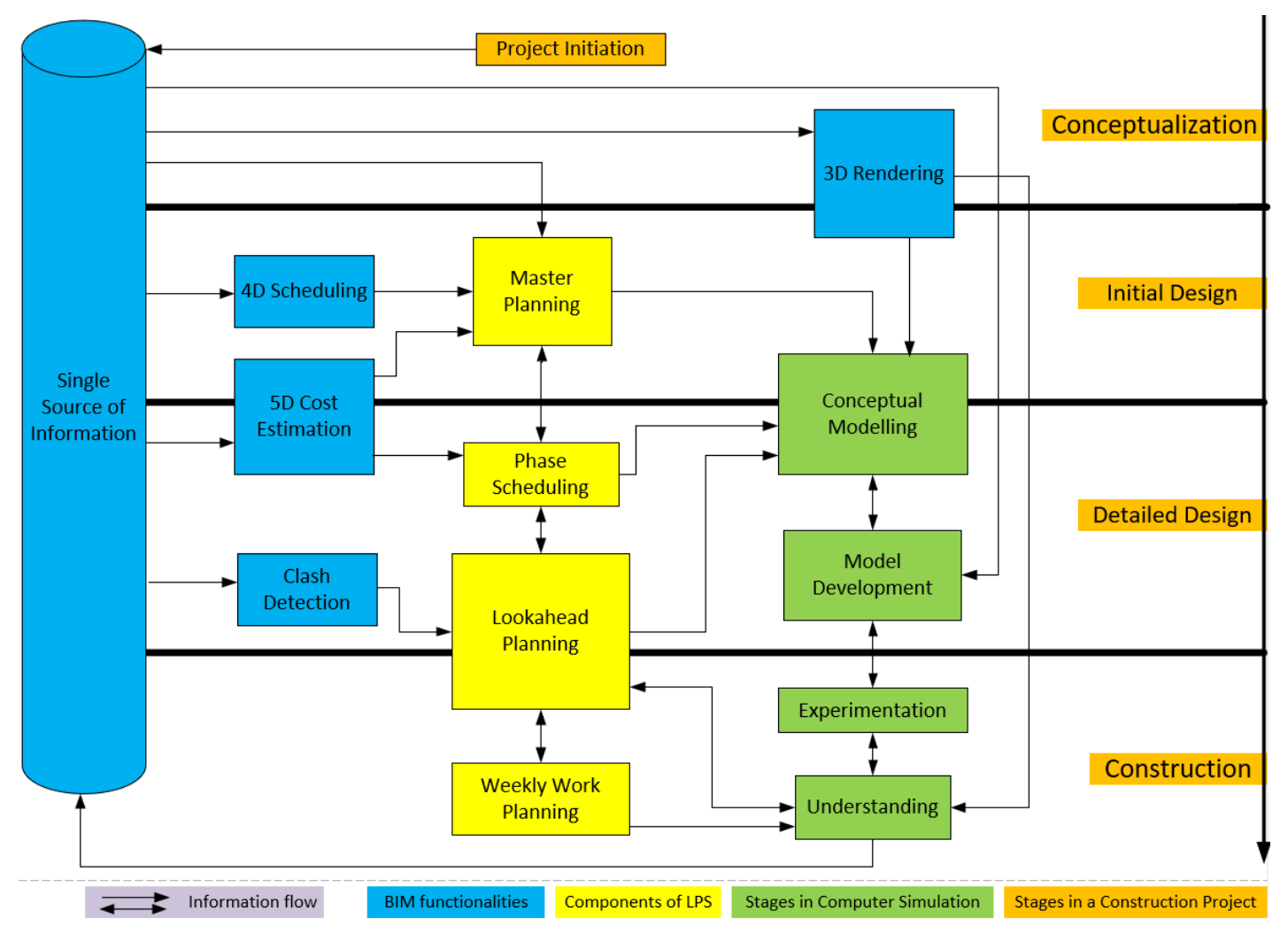

Figure 1: Conceptual integration framework linking BIM, LPS with CSM

The framework, as shown in Figure 1, begins with the conceptualization stage of a construction project, in which owners' requirements are recognized. Here, the concept design of the product is finalized. Data generated during this stage, such as customer needs and corresponding drawings and related BIM data can be stored in a cloud-based repository. The 3D visualization is an important BIM function (Sacks et al. 2010) that can be used in this stage to explicitly understand the owners' needs.

Next, the project moves to the initial design stage during which the basic design of the product is finalized. The $3 \mathrm{D}$ visualization function can help to compare alternative 
designs (Sacks et al. 2010). We argue that the master planning stage of the LPS can be started in this stage as all the activities of the master planning can be accomplished based on the basic design. To efficiently perform this phase, the 4D scheduling function of BIM can be used (Bhatla and Leite, 2004; Garrido et al., 2015). Also, the conceptual modeling phase of the CSM can be started within the initial design phase considering the inputs of the master plan (Abdelmegid et al., 2019). The 5D cost estimation BIM function can facilitate this stage to prepare the initial budget based on the master plan.

Subsequently, the detailed design stage is commenced, during which the schematic design is further upgraded by including specific design details. Those details can be stored and imported into, and reported from, the BIM information repository (Sacks et al. 2010). Based on that information, the project budget can be estimated in detail, and we argue that the 5D cost estimation function can play another important role in this regard. The phase scheduling and Lookahead Planning of the LPS can be started at this stage, having had all of their prerequisites fulfilled. To enhance the performance of Lookahead Planning, the clash detection BIM function (Garrido et al. 2015) can be used for which relevant data can be imported from the BIM information source. Also, we argue that the conceptual modeling phase can be finalized in this stage by having the inputs of phase scheduling and Lookahead Planning ready (Abdelmegid et al., 2019). The detailed design fulfils the requirements of planning a simulation study. Furthermore, development of the computer model can be started upon finalization of the conceptual modeling.

The final phase of the framework is Construction during which planning and execution of construction project activities happen. We argue that some activities, such as resource allocation and identifying workable backlogs, of Lookahead Planning can be linked to the planning function. The clash detection function of BIM can be used for constraint analyses that will support eliminating the existing constraints (Garrido et al. 2015). Simultaneously, simulation experiments can be performed to optimize resource allocation (Hamzeh et al. 2016; Abou-Ibrahim et al. 2019). The 3D visualization function of BIM can allow for a better understanding of simulation results (Sandoval et al. 2018). The Weekly Work Plan can be prepared and the work can be undertaken accordingly. For example, during the very first meeting, the simulation model can be run for the entire project considering different production planning scenarios so that the best production plan can be selected. Then, the work can be begun on-site according to the selected scenario. Moreover, the simulation analysis can be used not only as a production planning tool but also as a production control method, according to the progress of the project. The understanding gained from experimentations as well as learning acquired from the work implementation can be used for improving the reliability of future planning. Also, information related to experiments and learning can be stored in BIM server for upgrading the LPS and the simulation model (Abdelmegid et al. 2019).

\section{CONCLUSIONS}

We argue that the new framework will facilitate the use of CSM in construction projects by providing a platform for better decision making at the production level. Because this framework is enriched with components of BIM and LPS, it can capture the reality of a construction system to a great extent. Also, as many construction project stakeholders engage through this framework, the negative impact of poor simulation knowledge among construction practitioners on CSM can be alleviated.

In order to further develop this preliminary CSM framework, five research questions have been formulated: (1) How can appropriate functions of BIM be selected for 
facilitating with simulation of construction operations?; (2) How can suitable activities of LPS be selected for linking with the CSM?; (3) At what stages of the CSM process should selected elements of BIM and LPS be incorporated?; (4) How can the linkages between BIM and LPS be taken to develop a domain-specific CSM framework for construction?; and (5) How can the development of a CSM framework that integrates BIM and LPS improve the use of CSM by construction practitioners?

Next, the Design Science Research Methodology (DSRM) will be used for the further development of the new CSM framework. Under DSRM, serious games will be investigated as tools to both develop the framework and to demonstrate the applicability of the new CSM framework. Validation of the framework will be achieved by performing experiments with the participation of construction practitioners in a serious game-based experimental environment which has been developed based on the new CSM framework.

\section{REFERENCES}

Abdelmegid, M. A., González, V. A., O’Sullivan, M., Walker, C. G., Poshdar, M., and Alarcón, L. F. (2019). "Establishing a Link Between the Last Planner System and Simulation: A Conceptual Framework." Proc. 27th Annual Conference of the International Group for Lean Construction (IGLC), 335-246.

Abdelmegid, M. A., González, V. A., Poshdar, M., O’Sullivan, M., Walker, C. G., and Ying, F. (2020). "Barriers to adopting simulation modelling in construction industry." Automation in Construction, Elsevier, 111(June 2019), 103046.

Abou-Ibrahim, H., Hamzeh, F., Zankoul, E., Munch Lindhard, S., and Rizk, L. (2019). "Understanding the planner's role in lookahead construction planning." Production Planning \& Control, Taylor \& Francis, 30(4), 271-284.

AbouRizk, S., Halpin, D., Mohamed, Y., and Hermann, U. (2011). "Research in Modeling and Simulation for Improving Construction Engineering Operations." Journal of Construction Engineering and Management, 137(10), 843-852.

Al-Kaissy, M., Arashpour, M., Fayezi, S., Akbarnezhad, A., and Ashuri, B. (2019). "Process Modelling in Civil Infrastructure Projects: A Review of Construction Simulation Methods." Proceedings of the 36th International Symposium on Automation and Robotics in Construction (ISARC), 368-376.

Ballard, H. G. (2000). "THE LAST PLANNER SYSTEM OF PRODUCTION CONTROL." The University of Birmingham.

Bhatla, A., and Leite, F. (2012). "Integration Framework of BIM with the Last Planner System." 20th Annual Conference of the International Group for Lean Construction, I. D. Tommelein and C. L. Pasquire, eds., M.S., Department of Civil, Architectural and Environmental Engineering, University of Texas at Austin, 1 University Station C1752, Austin, TX 78712-0276, email: abhatla@utexas.edu.

Bokor, O., Florez, L., Osborne, A., and Gledson, B. J. (2019). "Overview of construction simulation approaches to model construction processes." Organization, Technology and Management in Construction: an International Journal, 11(1), 1853-1861.

Eastman, C., Teicholz, P., Sacks, R., and Liston, K. (2011). BIM handbook: A guide to building information modeling for owners, managers, designers, engineers and contractors. John Wiley \& Sons.

Eynon, J. (2016). Construction Manager's BIM Handbook. John Wiley \& Sons.

Garrido, M. C., Mendes, R., Scheer, S., and Campestrini, T. F. (2015). "Using BIM for Last Planner System: Case Studies in Brazil." Computing in Civil Engineering 2015, American Society of Civil Engineers, Reston, VA, 604-611. 
Gerges, M., Mayouf, M., Watson, P., Johns, G., Ahmed, E. K., Selim, O., and Wenman, B. (2019). "BIM Role within the Conceptual Design Phase: A Case Study of a UK Construction Project." International Journal of Architecture, Engineering and Construction, 8(1).

Gholizadeh, P., Esmaeili, B., and Goodrum, P. (2018). "Diffusion of Building Information Modeling Functions in the Construction Industry." Journal of Management in Engineering, 34(2), 04017060.

González, V., Alarcón, L. F., and Molenaar, K. (2009). "Multiobjective design of WorkIn-Process buffer for scheduling repetitive building projects." Automation in Construction, Elsevier B.V., 18(2), 95-108.

Gonzalez, V., Alarcon, L. F., and Mundaca, F. (2008). "Investigating the relationship between planning reliability and project performance." Production Planning \& Control, School of Engineering, Pontificia Universidad Católica de Chile, Santiago, Chile, 19(5), 461-474.

Hamzeh, F. R., El Samad, G., and Emdanat, S. (2019). "Advanced Metrics for Construction Planning." Journal of Construction Engineering and Management, 145(11), 04019063.

Hamzeh, F. R., Zankoul, E., and Rouhana, C. (2015). "How can 'tasks made ready' during lookahead planning impact reliable workflow and project duration?" Construction Management and Economics, Routledge, 33(4), 243-258.

Hamzeh, F., Zankoul, E., and Sakka, F. El. (2016). "Removing Constraints to Make Tasks Ready in Weekly Work Planning." Procedia Engineering, The Author(s), 164(June 2016), 68-74.

Heigermoser, D., García de Soto, B., Abbott, E. L. S., and Chua, D. K. H. (2019). "BIMbased Last Planner System tool for improving construction project management." Automation in Construction, Elsevier, 104(March), 246-254.

Hochscheid, E., and Halin, G. (2020). "Generic and SME-specific factors that influence the BIM adoption process: an overview that highlights gaps in the literature." Frontiers of Engineering Management, 7(1), 119-130.

Jeon, S. M., and Kim, G. (2016). "A survey of simulation modeling techniques in production planning and control (PPC)." Production Planning \& Control, Taylor \& Francis, 27(5), 360-377.

Jeong, W., Chang, S., Son, J., and Yi, J.-S. (2016). "BIM-Integrated Construction Operation Simulation for Just-In-Time Production Management." Sustainability, 8(11), 1106.

Jnitova, V., Elsawah, S., and Ryan, M. (2017). "Review of simulation models in military workforce planning and management context." The Journal of Defense Modeling and Simulation: Applications, Methodology, Technology, 14(4), 447-463.

Konig, M., Koch, C., Habenicht, I., and Spieckermann, S. (2012a). "Intelligent BIMbased construction scheduling using discrete event simulation." Proceedings Title: Proceedings of the 2012 Winter Simulation Conference (WSC), IEEE, 1-12.

Konig, M., Koch, C., Habenicht, I., and Spieckermann, S. (2012b). "Intelligent BIMbased construction scheduling using discrete event simulation." Proceedings Title: Proceedings of the 2012 Winter Simulation Conference (WSC), IEEE, 1-12.

Liu, H., Altaf, M. S., Lei, Z., Lu, M., and Al-Hussein, M. (2015). "automated production planning in panelized construction enabled by integrating discrete-event simulation and BIM." 5th International/11th Construction Specialty Conference, 1-10. 
Lu, W., and Olofsson, T. (2014). "Building information modeling and discrete event simulation: Towards an integrated framework." Automation in Construction, Elsevier B.V., 44, 73-83.

Naraghi, A. M., Gonzalez, V. A., O'sullivan, M., Walker, C. G., Poshdar, M., and Abdelmegid, M. A. (2017). "Implementation of Hybrid Simulation Modelling Framework in Construction." Lean and Computing in Construction Congress Volume 1: Proceedings of the Joint Conference on Computing in Construction, Heriot-Watt University, Edinburgh, 439-446.

Nikhil, M., Shingate, P., and Hedaoo, M. N. (2017). "Last Planner System-Theory to Implementation." IJSRD-International Journal for Scientific Research \& Development |, 5(09), 359-399.

Oskouie, P., Gerber, D. J., Alves, T., and Becerik-Gerber, B. (2012). "Extending the Interaction of Building Information modeling and lean construction." 20th Annual Conference of the International Group for Lean Construction, I. D. Tommelein and C. L. Pasquire, eds., Graduate Student, Sonny Astani Department of Civil and Environmental Engrg., University of Southern California, Los Angeles, CA 90089, USA, Phone+1 (213) 572-9373, oskouie@usc.edu.

Osorio Sandoval, C. A., Tizani, W., and Koch, C. (2018). "A method for discrete event simulation and building information modelling integration using a game engine." Advances in Computational Design, 3(4), 405-418.

Robinson, S. (2008). "Conceptual modelling for simulation Part I: definition and requirements." Journal of the Operational Research Society, 59(3), 278-290.

Robinson, S. (2014). Simulation: The Practice of Model Development and Use. Palgrave Macmillan, Basingstoke, UNITED KINGDOM.

Sacks, R., Eastman, C., Lee, G., and Teicholz, P. (2018). BIM Handbook: A Guide to Building Information Modeling for Owners, Designers, Engineers, Contractors, and Facility Managers. John Wiley \& Sons.

Sacks, R., Koskela, L., Dave, B. A., and Owen, R. (2010). "Interaction of Lean and Building Information Modeling in Construction." Journal of Construction Engineering and Management, 136(9), 968-980.

Salimi, S., Mawlana, M., and Hammad, A. (2018). "Performance analysis of simulationbased optimization of construction projects using High Performance Computing." Automation in Construction, Elsevier, 87(January), 158-172.

Salleh, S., Thokala, P., Brennan, A., Hughes, R., and Booth, A. (2017). "Simulation Modelling in Healthcare: An Umbrella Review of Systematic Literature Reviews." PharmacoEconomics, Springer International Publishing, 35(9), 937-949.

Sun, C., jiang, S., skibniewski, M. J., man, Q., and shen, L. (2015). “A LITERATURE REVIEW OF THE FACTORS LIMITING THE APPLICATION OF BIM IN THE CONSTRUCTION INDUSTRY." Technological and Economic Development of Economy, 23(5), 764-779.

Tillmann, P., and Sargent, Z. (2016). "Last planner \& BIM integration: Lessons from a continuous improvement effort." 24th Annual Conference of the International Group for Lean Construction, 113-122.

Toledo, M., Olivares, K., and González, V. (2016). "Exploration of a lean-BIM planning framework: A last planner system and BIM-based case study." 24th Annual Conference of the International Group for Lean Construction, 3-12.

Zaki, A. M., Abdelsalam, H. M., and El-Khodary, I. A. (2019). "A Simulation-Based Optimization Approach for Assessing Sustainability in a Multi-construction Projects 
Amila N. Wickramasekara, Vicente A. Gonzalez, Michael O’Sullivan, Cameron G. Walker, Mani Poshdar, and Fei Ying

Environment." Proceedings of the International Conference on Advanced Intelligent Systems and Informatics, Springer International Publishing, 556-566. 
Exploring the Integration of Last Planner ${ }^{\circledR}$ System, BIM, and Construction Simulation

This page was intentionally left blank. 